\title{
Influence of Time and Frequency of Passive Smoking Exposure on Mucociliary Clearance and the Autonomic Nervous System
}

\author{
Ana Paula CF Freire MSc, Dionei Ramos PhD, Marceli R Leite MSc, Bruna SA Silva MSc, \\ Renata M David, Juliana S Uzeloto, Francis L Pacagnelli PhD, Luiz Carlos M Vanderlei PhD, and \\ Ercy Mara C Ramos PhD
}

\begin{abstract}
BACKGROUND: There are still gaps in the knowledge regarding the damage to mucociliary and autonomous systems from passive exposure to cigarette smoke. Also, the influence of the frequency and duration of exposure on these systems is still unclear. The objective of this work was to verify the effects of passive smoking on mucociliary clearance and adult autonomic nervous systems and investigate the influence of frequency and time of passive exposure on these systems. METHODS: 44 smokers (smoking group), 38 passive smokers (passive smoking group), and 38 healthy individuals (control group) were evaluated. Evaluation of lung function was performed. To analyze the autonomic nervous system, heart rate variability data were collected. Hemodynamic parameters were collected. Mucociliary clearance was evaluated using the saccharin transit time test. RESULTS: The passive smoking group presented reduced lung function $(P=.02)$. Systolic blood pressure was significantly greater in the passive smoking group when compared with the smoking group $(P=.02)$. The passive smoking group presented significantly slower transportability time than the control group. No differences were observed between the groups for the heart rate variability data. There was a significant correlation $(P<.05)$ between the frequency of exposure and diastolic blood pressure, oxygen saturation, and $\mathrm{FEF}_{25-75 \%}$. Correlation analyses also demonstrated a reduction of global autonomic activity according to exposure load, in addition to a reduction in vagal activity and an increase in sympathetic activity according to exposure frequency. CONCLUSIONS: Passive smokers presented worse mucociliary clearance, and there was a correlation between passive exposure load and damage to the hemodynamic response, pulmonary function and autonomic nervous system. Key words: heart rate; mucociliary clearance; nervous system; smoking; tobacco smoke pollution. [Respir Care 2016;61(4):453-461. (C) 2016 Daedalus Enterprises]
\end{abstract}

\section{Introduction}

Smoking causes a significant increase in the risk of developing diseases in various systems of the body, ${ }^{1,2}$ of

\footnotetext{
Ms Freire, Ms Leite, Ms Silva, Ms David, and Ms Uzeloto are affiliated with the postgraduate Physical Therapy Program, São Paulo State University, Presidente Prudente, São Paulo, Brazil. Drs Dionei Ramos, Luiz Carlos M Vanderlei, and Ercy Mara C Ramos are affiliated with the Department of Physical Therapy, São Paulo State University, Presidente Prudente, São Paulo, Brasil. Dr Pacagnelli is affiliated with the Department of Physical Therapy, Oeste Paulista University, Presidente Prudente, São Paulo, Brasil.

This work was supported by the Fundação de Amparo a Pesquisa do Estado de São Paulo (FAPESP). The authors have disclosed no conflicts of interest.
}

which the damage caused in the respiratory and autonomic systems can be highlighted..$^{3,4}$

There are about 5,000 toxic chemicals in each cigarette. The majority of these components are inhaled by nonsmokers exposed to cigarette smoke and can reach the small airways of the respiratory tract due to the size of the particles in the smoke $(0.1-0.5 \mu \mathrm{m})$. Thus, the damage caused by smoking can be extended to passive smokers..$^{5-9}$

\footnotetext{
Correspondence: Ana Paula CF Freire MSc, Department of Physiotherapy, Roberto Simonsen 305, 19060-900, Presidente Prudente, SP, Brazil. E-mail: anapcff@hotmail.com.
}

DOI: $10.4187 /$ respcare. 04398 
The effects of exposure to cigarette smoke on mucociliary clearance and autonomic nervous systems in passive smokers has been investigated; these systems are considered mechanisms of great importance for the proper functioning of the body. ${ }^{4,10}$ The changes in these systems precipitated by active smoking are already established; however, the effects on passive smokers are not yet fully clear.

Habesoglu et al ${ }^{10}$ demonstrated in their study that the mucociliary clearance of adults exposed to cigarette smoke is impaired when compared with individuals without a history of exposure. This alteration may be related to decreased ciliary beat frequency and changes in the viscoelastic properties of mucus. In addition, it is believed that mucociliary clearance can be influenced by the action of the autonomic nervous system, which in turn, can also be modified by passive exposure to cigarette smoke. ${ }^{11}$

In a literature review, Valenti et al ${ }^{12}$ also demonstrated damage to the autonomic nervous system resulting from passive smoking, characterized by increased sympathetic activity and mitigated parasympathetic responses. However, the majority of the results found in this review were from animal studies, which limits the interpretation of the findings in humans. For this reason, the authors concluded that further studies were needed to clarify the alterations in the autonomic nervous system resulting from passive exposure. ${ }^{12}$

Given the above, it can be seen that there are still gaps in the knowledge relating to the damage caused by passive smoking on the mucociliary and autonomous systems, especially regarding the influence of the frequency and duration of exposure to cigarette smoke on these systems. ${ }^{9,10,12}$ It should be emphasized that despite the intensification of public policies established to reduce the harmful effects of passive smoking, individuals exposed in the home environment continue to be biased and need to be alerted to the potential damage. ${ }^{8-10}$ Therefore, the aim of this study was to investigate the effects of passive smoking on mucociliary clearance and the autonomic nervous system in adults and to investigate the influence of the frequency and duration of passive exposure on these systems.

\section{Methods}

This cross-sectional study evaluated 120 individuals, determined by sample size calculation (using a saccharin transit time test, with $80 \%$ test power and $95 \%$ confidence using an SD of 5.7, with a difference to be detected of 4, the sample calculation resulted in 32 individuals for each group), divided into 3 groups: 44 smokers enrolled in a smoking cessation program ${ }^{13}$ at the University of São Paulo, Brazil; 38 passive smokers exposed to cigarette smoke daily (family of the smokers group); and 38 volunteers in

\section{QUICK LOOK}

\section{Current knowledge}

The smoking habit causes a significant increase in the risk of developing diseases. The changes in mucociliary clearance and autonomic nervous systems in active smoking are already established. The damage caused by smoking can be extended to passive smokers.

\section{What this paper contributes to our knowledge}

This study demonstrated that there was impaired mucociliary clearance in passive smokers when compared with the control group. It was also found that there is an association between passive time and frequency of exposure and damage to the hemodynamic behavior, pulmonary function, and autonomic nervous system in these individuals.

the control group, recruited for the study. The study was conducted from March 2013 to July 2014.

The project was approved by the Committee for Ethics in Research of the Faculty of Science and Technology, UNESP, Presidente Prudente Campus-SP (Protocol CAAE: 07152212.0.0000.5402). All participants were informed about the objectives and procedures of the study and signed a consent form before being included in the study.

The study included individuals between 30 and $50 \mathrm{y}$ old of both sexes, without a diagnosis or history of lung or heart disease. The passive smoking group included individuals with a history of passive exposure to cigarette smoke for a minimum of $1 \mathrm{y}$ who did not present a history of active smoking or a profession involving direct contact with polluting agents. The smoking group included individuals with a smoking history of at least 20 cigarettes/d for a minimum of $1 \mathrm{y}$. The control group included individuals who did not present any history of continuous exposure to cigarette smoke or other pollutants or a history of active smoking.

Individuals with a history of surgery or nasal trauma, nasal septal deviation, or inflammation of the upper airways, verified by clinical evaluation and during the interview, were excluded. Physically active individuals (regular physical activity for $20 \mathrm{~min}$ at least 3 times/week) were excluded to avoid influences on mucociliary transportability. Those who did not attend one of the days of the experimental protocol were also excluded.

\section{Experimental Protocol}

The proposed protocol was performed over 2 days of evaluations. The first day of data collection consisted of 
the initial evaluation, including the individual's personal data and anthropometric measurements, in addition to spirometry to assess lung function in all groups.

On the second day of evaluation, in order to analyze the autonomic nervous system, the individuals were connected to a heart rate monitor to capture the heart rate variability data. Following this, the hemodynamic parameters were measured: breathing frequency, heart rate, $\mathrm{S}_{\mathrm{pO}_{2}}$, blood pressure, and the carbon monoxide measurement in exhaled air. Next, the mucociliary clearance rate of the volunteers was assessed using the saccharin transit time test.

Members of the active smoking group were requested to abstain from smoking for $12 \mathrm{~h}$ before attending the evaluations, and members of the passive smoking group were also asked to avoid family members while they were smoking for at least $12 \mathrm{~h}$ before the evaluations in order to detect only the effects already accumulated in the mucociliary clearance system and to eliminate the possibility of an outcome from an acute response.

\section{Initial Evaluation}

All participants were interviewed for information on several aspects: personal data, history of passive exposure and smoking history. The passive smokers received a questionnaire consisting of open questions about the smoking habits of their families and their perception of the effects of passive smoking on their health in order to perform qualitative analysis. The active smokers were questioned about their smoking habits, number of cigarettes per day, and number of years of smoking.

Subjects in the passive smoking group were asked whether they felt any symptoms or discomfort when inhaling cigarette smoke and, if so, what the symptoms were; they were also asked whether they felt biased in any way by passive exposure and how many times a day and for how many years they had been exposed to cigarette smoke. All participants were also questioned about their clinical history (surgery or nasal trauma, chronic respiratory disease, or infections during the previous few weeks). Finally, anthropometric measurements were collected (weight and height).

\section{Evaluation of Lung Function (Spirometry)}

For the measurement of lung function, spirometry was performed using a spirometer (Spirobank version 3.6, MIR, Rome, Italy) connected to a microcomputer. The criteria for the attainment, selection, and analysis of the curves were in accordance with the guidelines of the American Thoracic Society and European Respiratory Society. ${ }^{14}$ The normality values were according to the Brazilian population. ${ }^{15}$
All participants were instructed not to smoke (smoking group), not to be close to family smokers when they were smoking (passive smoking group), and not to drink caffeine-based substances for a minimum of $12 \mathrm{~h}$ before the evaluation. They were also advised to abstain from alcohol for at least $4 \mathrm{~h}$ and not to eat a large meal for $1 \mathrm{~h}$ before the spirometry test.

\section{Evaluation of Autonomic Nervous System Modulation}

The heart rate variability assessment was performed on the second day of the protocol, and data were collected for 20 min while the participants remained in a seated position. In order to capture heart rate, beat by beat, a recording strap was placed on the chest of the volunteers, and a heart rate receiver (S810i, Polar, Kempele, Finland) was placed on their wrist, and the data captured were used for analysis of heart rate variability. ${ }^{16,17}$

The heart rate variability data were analyzed at rest for $20 \mathrm{~min}$, and the first 256 breathing frequency intervals were used (oscillations in the interval between consecutive heartbeats) after digital filtering using Polar Precision Performance SW 4.01.029 software, complemented by manual filtering to eliminate premature ectopic beats and artifacts; only series with $>95 \%$ sinus beats were included in the study. ${ }^{18}$

Heart rate variability analysis was performed using linear methods, in the time domain, the frequency domain, and geometric indices. In the time domain, the RMSSD indices were used, which correspond to the root mean square of the successive differences between adjacent normal breathing frequency intervals, expressed in ms, representing the parasympathetic activity, and the SDNN, which is the SD of all normal breathing frequency intervals, expressed in ms, representing overall variability.

For analysis in the frequency domain, the spectral components of low frequency $(0.04-015 \mathrm{~Hz})(\mathrm{LF})$ were used, which reflect the joint action of the vagal and sympathetic components on the heart, with a predominance of the sympathetic. The high frequency $(0.15-0.40 \mathrm{~Hz})$ index $(\mathrm{HF})$, which represents parasympathetic activity in normalized units and $\mathrm{ms},{ }^{2}$ was also analyzed, together with the ratio of these components (LF/HF), which reflects the autonomic balance. ${ }^{19}$

For the analysis of geometric indices, the Poincaré plot was used, which is a diagram in which each breathing frequency interval is plotted as a function of the previous breathing frequency interval. The analysis was performed using the adjustment of the ellipse of the figure formed by the attractor, from which the following indices were calculated: SD1 (standard instantaneous beat-to-beat variability) representative of parasympathetic activity and SD2 (standard deviation of long term variability), which re- 
Table 1. Anthropometric and Spirometric Data of the Three Groups

\begin{tabular}{|c|c|c|c|c|}
\hline & $\begin{array}{l}\text { Passive Smoking Group } \\
\qquad(n=34)\end{array}$ & $\begin{array}{l}\text { Smoking Group } \\
\quad(n=37)\end{array}$ & $\begin{array}{l}\text { Control Group } \\
\quad(n=34)\end{array}$ & $P$ \\
\hline \multicolumn{5}{|l|}{ Anthropometry } \\
\hline Sex (male/female), $n$ & $10 / 24$ & $17 / 20$ & $15 / 19$ & \\
\hline Age, mean \pm SD y & $42.15 \pm 7.93$ & $40.54 \pm 6.24$ & $40.74 \pm 6.67$ & .58 \\
\hline Weight, mean $\pm \mathrm{SD}$ kg & $79.13 \pm 17.8$ & $73.99 \pm 15.93$ & $76.51 \pm 17.38$ & .40 \\
\hline Height, mean $\pm \mathrm{SD} \mathrm{cm}$ & $1.66 \pm 0.10$ & $1.67 \pm 0.08$ & $1.67 \pm 0.1$ & .86 \\
\hline $\mathrm{BMI}$, mean $\pm \mathrm{SD} \mathrm{kg} / \mathrm{m}^{2}$ & $28.27 \pm 5.1$ & $26.32 \pm 4.08$ & $27.29 \pm 5.37$ & .16 \\
\hline \multicolumn{5}{|l|}{ Spirometry } \\
\hline $\mathrm{FVC}$, mean $\pm \mathrm{SD} \mathrm{L}$ & $3.63 \pm 1.14$ & $4.00 \pm 0.75$ & $4.14 \pm 1.05$ & .12 \\
\hline $\mathrm{FVC}$, mean $\pm \mathrm{SD} \%$ predicted & $95.71 \pm 16.40$ & $100.4 \pm 11.39$ & $103.7 \pm 11.59$ & .068 \\
\hline $\mathrm{FEV}_{1}$, mean $\pm \mathrm{SD} \mathrm{L}$ & $2.93 \pm 0.86$ & $3.16 \pm 0.67$ & $3.36 \pm 0.77$ & .10 \\
\hline $\mathrm{FEV}_{1}$, mean $\pm \mathrm{SD} \%$ predicted & $93.41 \pm 14.90$ & $94.67 \pm 12.86$ & $101.9 \pm 9.81^{*}$ & .02 \\
\hline $\mathrm{FEV}_{1} / \mathrm{FVC}$, mean $\pm \mathrm{SD}$ & $81.43 \pm 5.32$ & $80.02 \pm 5.48$ & $81.78 \pm 5.13$ & .35 \\
\hline $\mathrm{FEV}_{1} / \mathrm{FVC}$, mean $\pm \mathrm{SD} \%$ predicted & $98.57 \pm 6.20$ & $96.87 \pm 6.09$ & $99.12 \pm 6.04$ & .29 \\
\hline $\mathrm{FEF}_{25-75 \%}$, mean $\pm \mathrm{SD} \mathrm{L} / \mathrm{s}$ & $3.08 \pm 0.96$ & $3.08 \pm 1.02$ & $3.39 \pm 0.76$ & .37 \\
\hline $\mathrm{FEF}_{25-75 \%}$, mean $\pm \mathrm{SD} \%$ predicted & $95.14 \pm 24.60$ & $90.10 \pm 28.01$ & $100.6 \pm 20.78$ & .26 \\
\hline
\end{tabular}

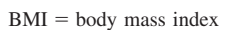

* Difference between passive smoking and control groups.

flects the overall variability. ${ }^{16,17}$ Heart rate variability analysis software (Kubios, Biosignal Analysis and Medical Image Group, Department of Physics, University of Kuopio, Finland) was used to determine these indices. ${ }^{18}$ All of the participants were instructed not to smoke (smoking group) or ingest caffeine-based substances and to abstain from alcohol for at least $12 \mathrm{~h}$ before the assessment and avoid large meals for $1 \mathrm{~h}$ before the evaluation.

\section{Measurement of Vital Signs}

The respiratory frequency was measured by observing the number of expansions of the rib cage while watching the respiratory mechanics of the individual for $1 \mathrm{~min}$. The heart rate was determined using a heart rate monitor (S810i). Oxygen saturation was assessed by means of a finger oximeter (NewTech, Guangdong, China). For measurement of blood pressure, auscultation was performed in the left arm, using an aneroid sphygmomanometer and stethoscope (BD Biosciences, São Paulo, Brazil). ${ }^{20}$ All vital signs were collected after 20 min of rest.

\section{Measurement of Carbon Monoxide in Exhaled Air}

The carbon dioxide measurement was performed after an initial measurement of vital signs. The volunteer was instructed to inhale deeply with breath hold for $20 \mathrm{~s}$. Next, a device (Micro Medical, Rochester, United Kingdom) that measures the concentration of carbon monoxide exhaled through an electrochemical sensor, expressing it in ppm and percentage of carboxyhemoglobin, was placed in

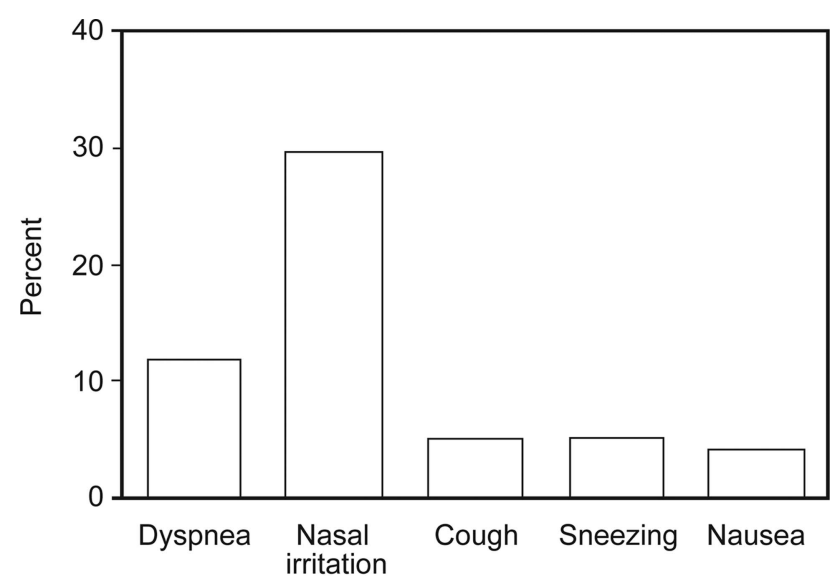

Fig. 1. The presence of symptoms reported by the passive smoking group when inhaling.

the mouth of each volunteer, and they were instructed to perform a slow and gentle full expiration. ${ }^{21}$

\section{Measurement of Nasal Mucociliary Clearance (Saccharin Transit Time Test)}

The mucociliary clearance evaluation was performed using the saccharin transit time test. The participants were seated with their head extended at $10^{\circ}$. The saccharin transit time test was initiated by introducing approximately $250 \mu \mathrm{g}$ of granulated sodium saccharin through a plastic straw, under visual control, approximately $2 \mathrm{~cm}$ into the right nostril. The chronometer was started from this moment; the subjects were instructed not to walk, talk, cough, sneeze, scratch, or blow their nose; and they were in- 
Table 2. Hemodynamic Parameters, Carbon Monoxide Monitor Levels, and Mucociliary Clearance of the Three Groups

\begin{tabular}{|c|c|c|c|c|}
\hline & Passive Smoking Group & Smoking Group & Control Group & $P$ \\
\hline \multicolumn{5}{|l|}{ Hemodynamic parameters } \\
\hline $\mathrm{SBP}, \mathrm{mm} \mathrm{Hg}$ & $\begin{array}{c}119.1 \pm 14.85 \\
120(110-122.5)\end{array}$ & $\begin{array}{r}111.1 \pm 13.71 * \\
110(100-120)\end{array}$ & $\begin{array}{c}111.7 \pm 10.31 \\
110(100-120)\end{array}$ & .02 \\
\hline $\mathrm{DBP}, \mathrm{mm} \mathrm{Hg}$ & $\begin{array}{l}75.59 \pm 11.33 \\
80(70-80)\end{array}$ & $\begin{array}{c}74.47 \pm 10.05 \\
80(70-80)\end{array}$ & $\begin{array}{c}74.09 \pm 9.587 \\
70(70-80)\end{array}$ & .81 \\
\hline Heart rate, beats/min & $\begin{array}{l}74.32 \pm 15.61 \\
75(65-84.50)\end{array}$ & $\begin{array}{l}73.39 \pm 9.64 \\
73(67.75-79.25)\end{array}$ & $\begin{array}{l}75.47 \pm 14 \\
75(70-83.50)\end{array}$ & .45 \\
\hline Frequency, breaths/min & $\begin{array}{l}18.47 \pm 2.873 \\
20(16-20)\end{array}$ & $\begin{array}{r}18.42 \pm 2.64 \\
18(16-20)\end{array}$ & $\begin{array}{c}19.30 \pm 12.12 \\
16(16-20)\end{array}$ & .30 \\
\hline $\mathrm{S}_{\mathrm{pO}_{2}}, \%$ & $\begin{array}{l}97.85 \pm 1.105 \\
98(97-99)\end{array}$ & $\begin{array}{c}97.55 \pm 1.483 \\
98(97-99)\end{array}$ & $\begin{array}{r}97.71 \pm 1.08 \\
98(97-99)\end{array}$ & .67 \\
\hline \multicolumn{5}{|l|}{ Carbon monoxide monitor } \\
\hline COex, ppm & $\begin{array}{c}1.647 \pm 2.373 \\
0(0-2.0)\end{array}$ & $\begin{array}{c}6.73 \pm 3.45^{*} \\
7(4-10)\end{array}$ & $\begin{array}{c}1.676 \pm 1.512 \ddagger \\
1(0-3)\end{array}$ & $<.001$ \\
\hline COex, $\% \mathrm{COHb}$ & $\begin{array}{c}0.2635 \pm 0.3796 \\
0(0-0.32)\end{array}$ & $\begin{array}{c}1.35 \pm 0.82 * \\
1.28(0.76-2.08)\end{array}$ & $\begin{array}{c}0.36 \pm 0.44 \ddagger \\
0.24(0-0.48)\end{array}$ & $<.001$ \\
\hline \multicolumn{5}{|l|}{ Mucociliary clearance } \\
\hline STT, min & $\begin{array}{c}13.24 \pm 5.755 \\
11.73(8.68-18.62)\end{array}$ & $\begin{array}{c}11.55 \pm 5.696 \\
10.01(6.80-14.75)\end{array}$ & $\begin{array}{l}9.85 \pm 6.89 \S \\
7.87(5.36-13.52)\end{array}$ & .02 \\
\hline \multicolumn{5}{|c|}{$\begin{array}{l}\text { Data are expressed as mean } \pm \mathrm{SD} \text { and as median (interquartile range). } \\
\text { SBP }=\text { systolic blood pressure } \\
\text { DBP }=\text { diastolic blood pressure } \\
\text { COex }=\text { carbon monoxide in exhaled air } \\
\text { COHb }=\text { carboxyhemoglobin } \\
\text { STT }=\text { saccharin transit time } \\
\text { * Significant difference between passive smoking and smoking groups. } \\
\text { † Significant difference between smoking and control groups. } \\
\text { \& Significant difference between passive smoking and control groups. }\end{array}$} \\
\hline
\end{tabular}

structed to swallow a few times/min until they felt the taste in their mouth, at which time the examiner was immediately alerted by a gesture from the participant being assessed, and the time was recorded. ${ }^{22}$

\section{Statistical Analysis}

The data were analyzed using the statistical software GraphPad Prism (GraphPad Software, San Diego, California). Initially, the Shapiro-Wilk test was performed to assess the normality of the data. To compare the 3 groups analyzed, the one-way analysis of variance test was used with Tukey's post-test for data considered parametric, and the Kruskal-Wallis test and the Dunn post-test were used for nonparametric data. For correlation analysis, the Pearson or Spearman test was used according to the normality of the data. The level of significance used was 5\%. Data were expressed as mean, SD, median, and interquartile range according to data normality.

\section{Results}

A total of 120 individuals were evaluated; however, 15 individuals were excluded for not meeting the proposed inclusion criteria or for missing one of the days of the experimental protocol. Thus, the passive smoking group ended with 34 individuals, the smoking group with 37 subjects, and the control group with 34 subjects with no history of passive or active smoking exposure.

The anthropometric characteristics of the 3 groups together with the pulmonary function analysis can be seen in Table 1. The passive smoking group had an average time of exposure to cigarette smoke of $19.08 \pm 13.19 \mathrm{y}$, with a daily exposure frequency of $7.66 \pm 8.7$ times. The smoking group presented an active smoking history of $21.1 \pm 8.53 \mathrm{y}$ and consumption of $26.5 \pm 26.9$ cigarettes/d.

From the qualitative analysis of the open questions to the passive smoking group, it was reported that $55.9 \%$ of the individuals felt some damage to health related to passive exposure. In addition, $67.6 \%$ felt some symptom when inhaling cigarette smoke. Among the reported symptoms were dyspnea, nose irritation (itching, burning, or nasal congestion), coughing, sneezing, and nausea. The data can be seen in Figure 1.

Table 2 presents a comparison of the results of hemodynamic parameters, carbon monoxide monitoring, and mucociliary clearance of the 3 groups. In relation to the 
Table 3. Indices of Heart Rate Variability in the Three Groups

\begin{tabular}{|c|c|c|c|c|}
\hline & Passive Smoking Group & Smoking Group & Control Group & $P$ \\
\hline \multirow[t]{2}{*}{ SDNN } & $37.60 \pm 17.65$ & $37.47 \pm 17.19$ & $37.36 \pm 15.66$ & .92 \\
\hline & $37.25(24.10-48.58)$ & $33.30(27.40-43.90)$ & $36.5(23.65-47)$ & \\
\hline \multirow[t]{2}{*}{ RMSSD } & $25.31 \pm 13.31$ & $25.42 \pm 13.20$ & $24.15 \pm 13.03$ & .75 \\
\hline & $25.40(13.15-36.38)$ & $21.80(16.60-31.90)$ & $21.9(14.65-27.75)$ & \\
\hline \multirow[t]{2}{*}{$\mathrm{LF}, \mathrm{ms}^{2}$} & $533.3 \pm 564.2$ & $452.4 \pm 612.2$ & $594.8 \pm 603.1$ & .47 \\
\hline & $308(191.5-712)$ & 257 (179-507) & $389(160-860)$ & \\
\hline \multirow[t]{2}{*}{ LF, nu } & $62.77 \pm 19.33$ & $62.77 \pm 19.33$ & $64.73 \pm 19.04$ & .88 \\
\hline & $66.5(38-80.33)$ & $64.2(45-79)$ & $65.60(50.75-81.85)$ & \\
\hline \multirow[t]{2}{*}{$\mathrm{HF}, \mathrm{ms}^{2}$} & $338.2 \pm 330.9$ & $297.7 \pm 373.4$ & $333.8 \pm 464.9$ & .63 \\
\hline & $269.5(78-534.5)$ & $183(91-381)$ & $179(71-358.5)$ & \\
\hline \multirow[t]{2}{*}{ HF, nu } & $36.69 \pm 18.38$ & $36.69 \pm 18.38$ & $35.27 \pm 19.04$ & .89 \\
\hline & $27.9(17.55-56.30)$ & $35.8(21-55)$ & $34.4(18.15-49.25)$ & \\
\hline \multirow[t]{2}{*}{$\mathrm{LF} / \mathrm{HF}$} & $2.797 \pm 3.191$ & $4.024 \pm 6.502$ & $4.009 \pm 6.388$ & .99 \\
\hline & $2.294(0.7788-4.356)$ & $2.042(0.99-3.923)$ & $1.906(1.031-4.548)$ & \\
\hline \multirow[t]{2}{*}{ SD1 } & $17.93 \pm 9.416$ & $18.01 \pm 9.329$ & $17.12 \pm 9.246$ & .76 \\
\hline & $18(9.3-25.73)$ & $15.4(11.8-22.6)$ & $15.5(10.35-19.70)$ & \\
\hline \multirow[t]{2}{*}{ SD2 } & $49.65 \pm 23.94$ & $49.44 \pm 23.33$ & $49.66 \pm 20.95$ & .94 \\
\hline & $47.35(30.73-66.10)$ & $43.30(36.8-57.3)$ & $49.2(31.45-61.8)$ & \\
\hline \\
\hline \multirow{2}{*}{\multicolumn{5}{|c|}{$\begin{array}{l}S D N N=S D \text { of normal to normal breathing frequency intervals, expressed in ms } \\
\text { RMSSD }=\text { root mean square of successive differences between adjacent normal breathing frequency intervals for a period of time, expressed in ms } \\
L F=\text { low frequency }\end{array}$}} \\
\hline & & & & \\
\hline $\begin{array}{l}\mathrm{LF}=\text { low frequency } \\
\mathrm{nu}=\text { normalized units }\end{array}$ & & & & \\
\hline \multicolumn{5}{|c|}{$\mathrm{HF}=$ high frequency } \\
\hline $\mathrm{SD} 1=\mathrm{SD} 0$ & ariability beat to beat & & & \\
\hline $\mathrm{SD} 2=\mathrm{SD} 0$ & & & & \\
\hline
\end{tabular}

heart rate variability data (Table 3), no significant differences were observed for any of the analyzed indices.

Correlation analyses were performed between the frequency of exposure (exposure times daily) and the exposure time (in years): hemodynamic parameters, carbon monoxide monitoring, spirometric values, mucociliary clearance, and heart rate variability indices. The results of these analyses can be seen in Table 4. There was a significant correlation $(P<.05)$ between the frequency of exposure and diastolic blood pressure, oxygen saturation, and $\mathrm{FEF}_{25-75 \%}$ and between the following heart rate variability indices: RMSSD, LF (normalized units), HF (ms) HF (normalized units), LF/HF, and SD1. In the correlations with the exposure time (years) a significant association was found only with the SDNN, LF (ms), and SD2 $(P<.05)$.

\section{Discussion}

The principal findings of this study demonstrated that there was impaired mucociliary clearance in passive smokers when compared with the control group. It was also found that there is an association between passive exposure time and frequency of exposure and damage to the hemodynamic, pulmonary function, and autonomic nervous system in these individuals.
It was observed that the passive smokers presented reduced lung function, characterized by a decrease in $\mathrm{FEV}_{1}$ values, compared with the control group. In addition, there was a negative correlation between the frequency of exposure and $\mathrm{FEF}_{25-75 \%}$. These findings may be associated with the increased formation of free radicals when exposed to pollutants, starting an inflammatory reaction and releasing inflammatory cells and mediators (cytokines, chemokines, and adhesion molecules) that reach systemic circulation, leading to a subclinical inflammation, not only with repercussions in the respiratory system, but also causing systemic effects. ${ }^{23,24}$

Thus, it is believed that with an increased exposure to load, there is a potentiation of these harmful effects. Thus, the reduction in pulmonary function may result in an increased risk of hospitalization, a prevalence of respiratory symptoms, and even death. ${ }^{25}$

Regarding the hemodynamic behavior, the passive smoking group presented higher systolic blood pressure values compared with the smoking group $(P=.02)$. Although the average values were considered normal, ${ }^{13}$ these data become alarming when considering that previous studies 26,27 have shown that people exposed to cigarette smoke have higher chances of developing hypertension. In addition, the sample in the present study 
Table 4. Correlation Analyses Between Passive Exposure Load and Hemodynamic Parameters, Carbon Monoxide Monitor Levels, Spirometric Indices, Mucociliary Clearance, and Heart Rate Variability Indices

\begin{tabular}{|c|c|c|c|c|}
\hline & \multicolumn{4}{|c|}{ Passive Smoking Group } \\
\hline & \multicolumn{2}{|c|}{$\begin{array}{c}\text { Frequency of } \\
\text { Exposure }\end{array}$} & \multicolumn{2}{|c|}{$\begin{array}{l}\text { Time of } \\
\text { Exposure }\end{array}$} \\
\hline & $\mathrm{r}$ & $P$ & $\mathrm{r}$ & $P$ \\
\hline \multicolumn{5}{|l|}{ Hemodynamic parameters } \\
\hline $\mathrm{SBP}, \mathrm{mm} \mathrm{Hg}$ & 0.23 & .20 & 0.09 & .60 \\
\hline $\mathrm{DPB}, \mathrm{mm} \mathrm{Hg}$ & 0.35 & .044 & 0.10 & .59 \\
\hline Heart rate, beats/min & 0.30 & .09 & -0.23 & .20 \\
\hline Frequency, breaths/min & 0.27 & .13 & -0.08 & .65 \\
\hline $\mathrm{S}_{\mathrm{pO}_{2}}, \%$ & -0.36 & .038 & -0.01 & .94 \\
\hline \multicolumn{5}{|l|}{ Carbon monoxide monitor } \\
\hline COex, ppm & -0.01 & .96 & -0.03 & .85 \\
\hline $\mathrm{COex}, \% \mathrm{COHb}$ & -0.01 & .96 & -0.03 & .85 \\
\hline \multicolumn{5}{|l|}{ Spirometry } \\
\hline FVC, L & -0.27 & .16 & -0.33 & .08 \\
\hline FVC, $\%$ predicted & -0.27 & .16 & -0.31 & .11 \\
\hline $\mathrm{FEV}_{1}, \mathrm{~L}$ & -0.32 & .09 & -0.35 & .063 \\
\hline $\mathrm{FEV}_{1}, \%$ predicted & -0.32 & .09 & -0.25 & .19 \\
\hline $\mathrm{FEV}_{1} / \mathrm{FVC}$ & -0.11 & .56 & 0.06 & .74 \\
\hline $\mathrm{FEV}_{1} / \mathrm{FVC}, \%$ predicted & -0.02 & .94 & 0.21 & .27 \\
\hline $\mathrm{FEF}_{25-75 \%}, \mathrm{~L} / \mathrm{s}$ & -0.37 & .046 & -0.22 & .25 \\
\hline $\mathrm{FEF}_{25-75 \%}, \%$ predicted & -0.24 & .21 & 0.05 & .80 \\
\hline \multicolumn{5}{|l|}{ Mucociliary clearance } \\
\hline $\mathrm{STT}, \min$ & 0.05 & .78 & 0.26 & .14 \\
\hline \multicolumn{5}{|l|}{ Heart rate variability } \\
\hline SDNN & -0.29 & .13 & -0.46 & .01 \\
\hline RMSSD & -0.44 & .02 & -0.32 & .09 \\
\hline $\mathrm{LF}, \mathrm{ms}^{2}$ & -0.11 & .58 & -0.48 & .009 \\
\hline $\mathrm{LF}, \mathrm{nu}$ & 0.42 & .02 & 0.12 & .54 \\
\hline $\mathrm{HF}, \mathrm{ms}^{2}$ & -0.49 & .01 & -0.31 & .10 \\
\hline $\mathrm{HF}, \mathrm{nu}$ & -0.51 & .005 & -0.24 & .20 \\
\hline $\mathrm{LF} / \mathrm{HF}$ & 0.50 & .006 & 0.12 & .52 \\
\hline SD1 & -0.44 & .02 & -0.32 & .09 \\
\hline $\mathrm{SD} 2$ & -0.26 & .18 & -0.47 & .01 \\
\hline \multicolumn{5}{|l|}{$\overline{\text { SBP }=\text { systolic blood pressure }}$} \\
\hline \multicolumn{5}{|l|}{ DBP $=$ diastolic blood pressure } \\
\hline \multicolumn{5}{|l|}{ COex $=$ carbon monoxide in exhaled air } \\
\hline \multicolumn{5}{|l|}{$\mathrm{COHb}=$ carboxyhemoglobin } \\
\hline \multicolumn{5}{|l|}{ STT $=$ saccharin transit time } \\
\hline \multirow{2}{*}{\multicolumn{5}{|c|}{$\begin{array}{l}\text { SDNN }=\text { SD of normal to normal breathing frequency intervals, expressed in } \mathrm{ms} \\
\text { RMSSD = root mean square of successive differences between adjacent normal breathing } \\
\text { frequency intervals for a period of time, expressed in ms }\end{array}$}} \\
\hline & & & & \\
\hline \multirow{2}{*}{\multicolumn{5}{|c|}{$\begin{array}{l}\mathrm{LF}=\text { low frequency } \\
\end{array}$}} \\
\hline & & & & \\
\hline \multicolumn{4}{|l|}{$\mathrm{HF}=$ high frequency } & $\begin{array}{l}\mathrm{nu}=\text { normalized unit } \\
\mathrm{HF}=\text { high frequency }\end{array}$ \\
\hline \multicolumn{5}{|c|}{ SD1 $=$ SD of the instantaneous variability beat to beat } \\
\hline
\end{tabular}

consisted of sedentary individuals, a factor that can aggravate the pre-hypertensive state, leading to more serious cardiovascular impairments.

Felber Dietrich et al ${ }^{28}$ also evaluated blood pressure in passive smokers; however, they did not observe significant changes in this index. It is believed that this difference in findings from the present study is due to differences in the study population inclusion criteria, since, in the present investigation, we did not include individuals with a history of active smoking in the passive smoking group or physically active individuals. Also, in the study of Felber Dietrich et al, ${ }^{28}$ it was observed that passive smokers with a higher exposure load had higher blood pressure levels, which corroborates the findings of this study. Such behavior may be related to the increase in sympathetic activity demonstrated in the literature. ${ }^{3,11}$

In the analysis of saccharin transit time, a longer transportability time was observed in groups of active and passive smokers; however, there was a significant difference only in the comparison between the control group and passive smoking group $(P=.02)$. This finding demonstrates alterations in the functioning of the mucociliary clearance of individuals subjected to passive exposure, an alarming fact considering that this transport is the main defense mechanism of the respiratory system against harmful agents and particles. ${ }^{5,29}$ Exposure to cigarette smoke can cause damage to the structure of the cilia that compose part of this system, in addition to changing the viscoelastic properties of mucus. These alterations can significantly increase the risk of respiratory complications, such as infections, and respiratory symptoms. . $22,29,30^{2}$

Habesoglu et $\mathrm{al}^{10}$ found similar results to the present study; however, the individuals evaluated in their study were younger and had a higher frequency of exposure to cigarette smoke ( $>10$ cigarettes/d). In the present study, it was observed that even lower levels of exposure are able to promote damage in mucociliary clearance.

In the analysis of the autonomic nervous system, no significant differences were observed when comparing the 3 groups. However, the correlation analysis in the passive smoking group demonstrated that there was a global reduction in the autonomic activity according to the time and frequency of exposure, characterized by a negative correlation in the SDNN and SD2 indices. A reduction in vagal activity (RMSSD, HF, and SD1) and increased sympathetic activity (LF and LF/HF ratio) was also observed, according to the frequency of exposure. This set of behaviors indicates that there is influence of time and frequency of passive exposure on autonomic modulation of adults.

The literature suggests that passive exposure is related to changes in the autonomic nervous system. ${ }^{12,28}$ This mechanism is associated with the action of nicotine, present in cigarette smoke, which is responsible for promoting sympathetic activation with the release of catecholamines, which cause acute and chronic cardiovascular effects, such as increased heart rate and blood pressure, in addition to increased oxygen demand and overload in the myocardium..$^{2,4}$ 
The increased sympathetic activity at rest has been identified as an indicator of poor adaptation of the autonomic nervous system and a risk factor for arrhythmias and sudden death. It is believed that these findings may be related to the low level of exposure to cigarette smoke reported in this study compared with other studies in the review by Valenti et $\mathrm{al}^{12}$ and the study of Felber Dietrich et al ${ }^{28}$

In the qualitative analysis, it was observed that 55.9\% reported feeling harmed by passive exposure; in addition, $67.6 \%$ felt some discomfort or symptoms while inhaling the cigarette smoke. Because no studies were found that qualitatively evaluated the perception of individuals exposed to cigarette smoke, it is believed that this analysis is of great importance to better understand the extent of the damage caused by passive smoking.

The results of the present study add important information to the scientific knowledge of the harm caused by passive smoking. The impairment in the mucociliary system and the relationship between passive exposure load and autonomic activity demonstrated in this study reinforce the idea that it is necessary to implement more public policies to minimize the damage caused by passive smoking, such as smoking cessation programs, considered the most effective method to reduce the number of smokers and hence reduce exposure.

\section{Conclusion}

It is concluded that passive smokers present impairments in mucociliary clearance. A correlation was also found between passive exposure load and damage to the hemodynamic, pulmonary function, and autonomic nervous system.

\section{REFERENCES}

1. WHO Report on the Global Tobacco Epidemic, 2008: The M POWER package. Geneva: Word Health Organization; 2008.

2. Messner B, Bernhard D. Smoking and cardiovascular disease: mechanisms of endothelial dysfunction and early atherogenesis. Arterioscler Thromb Vasc Biol 2014;34(3):509-515.

3. Milner D. The physiological effects of smoking on the respiratory system. Nurs Times 2004;100(24):56-59.

4. Middlekauff HR, Park J, Moheimani RS. Adverse effects of cigarette and noncigarette smoke exposure on the autonomic nervous system: mechanisms and implications for cardiovascular risk. J Am Coll Cardiol 2014;64(16):1740-1750.

5. Liu Y, Di YP. Effects of second hand smoke on airway secretion and mucociliary clearance. Front Physiol 2012;3:342.

6. Campbell RC, Stephens WE, Meharg AA. Consistency of arsenic speciation in global tobacco products with implications for health and regulation. Tob Induc Dis 2014;12(1):24.

7. Domagala-Kulawik J. Effects of cigarette smoke on the lung and systemic immunity. J Physiol Pharmacol 2008;59(Suppl 6):19-34.

8. Kumar SR, Davies S, Weitzman M, Sherman S. A review of air quality, biological indicators and health effects of second-hand waterpipe smoke exposure. Tob Control 2015;24(Suppl 1):i54-i59.
9. Jones MR, Barnoya J, Stranges S, Losonczy L, Navas-Acien A. Cardiovascular events following smoke-free legislations: an updated systematic review and meta-analysis. Curr Environ Health Rep 2014; 1(3):239-249.

10. Habesoglu M, Demir K, Yumusakhuylu AC, Yilmaz AS, Oysu C. Does passive smoking have an effect on nasal mucociliary clearance? Otolaryngol Head Neck Surg 2012;147(1):152-156.

11. Wanner A. Autonomic control and mucociliary functions. Chest 1987; 91(5 Suppl):49S-51S.

12. Valenti VE, Vanderlei LC, Ferreira C, Fonseca FL, Oliveira FR, Sousa FH, et al. Sidestream cigarette smoke and cardiac autonomic regulation. Int Arch Med 2013;6(1):11.

13. Freire APCF, Ramos D, Silva BSA, David RM, Pestana PRS, Fernandes RA, et al. Resultados de um programa de cessação tabagística: análise de novos procedimentos. ConScientiae Saúde 2014; 13(3):396-404.

14. Miller MR, Hankinson J, Brusasco V, Burgos F, Casaburi R, Coates A, et al. Standardization of spirometry. Eur Respir J 2005;26(2):319338.

15. Neder JA, Andreoni S, Castelo-Filho A, Nery LE. Reference values for lung function tests. I. Static volumes. Braz J Med Biol Res 1999;32(6):703-717.

16. Vanderlei LCM, Pastre CM, Hoshi RA, Carvalho TD, Godoy MF. Noções básicas de variabilidade da frequência cardíaca e sua aplicabilidade clínica. Rev Bras Cir Cardiovasc 2009;24(2):205217.

17. Vanderlei LCM, Silva RA, Pastre CM, Azevedo FM, Godoy MF. Comparison of the Polar S810i monitor and the ECG for the analysis of heart rate variability in the time and frequency domains. Braz J Med Biol Res 2008;41(10):854-859.

18. Godoy MF, Takakura IT, Correa PR. Relevância da análise do comportamento dinâmico não linear (Teoria do Caos) como elemento prognóstico de morbidade e mortalidade em pacientes submetidos à cirurgia de revascularização miocárdica. Arq Ciênc Saúde 2005; 12(4):167-171.

19. Manzano BM, Vanderlei LC, Ramos EM, Ramos D. Acute effects of smoking on autonomic modulation: analysis by Poincaré plot. Arq Bras Cardiol 2011;96(2):154-160.

20. V Diretrizes Brasileiras de Hipertensão Arterial. Revista da Sociedade Brasileira de Hipertensão 2006;9(4):121-157.

21. Jatlow P, Toll BA, Leary V, Krishnan-Sarin S, O'Malley SS. Comparison of expired carbon monoxide and plasma cotinine as markers of cigarette abstinence. Drug Alcohol Depend 2008;98(3): 203-209.

22. Salah B, Dinh Xuan AT, Fouilladieu JL, Lockhart A, Regnard J. Nasal mucociliary transport in healthy subjects is slower when breathing dry air. Eur Respir J 1(9)988;1:852-855.

23. Pope D, Diaz E, Smith-Sivertsen T, Lie RT, Bakke P, Balmes JR, et al. Exposure to household air pollution from wood combustion and association with respiratory symptoms and lung function in nonsmoking women: results from the RESPIRE trial, Guatemala. Environ Health Perspect 2015;123(4):285-292.

24. Lugade AA, Bogner PN, Thatcher TH, Sime PJ, Phipps RP, Thanavala Y. Cigarette smoke exposure exacerbates lung inflammation and compromises immunity to bacterial infection. J Immunol 2014; 192(11):5226-5235.

25. Perez-Padilla R, Schilmann A, Riojas-Rodriguez H. Respiratory health effects of indoor air pollution. Int J Tuberc Lung Dis 2010; 14(9):1079-1086.

26. Makris TK, Thomopoulos C, Papadopoulos DP, Bratsas A, Papazachou O, Massias S, et al. Association of passive smoking with masked hypertension in clinically normotensive nonsmokers. Am J Hypertens 2009;22(8):853-859. 


\section{Effects of Passive SMoking}

27. Yarlioglues M, Kaya MG, Ardic I, Calapkorur B, Dogdu O, Akpek $\mathrm{M}$, et al. Acute effects of passive smoking on blood pressure and heart rate in healthy females. Blood Press Monit 2010;15(5):251256.

28. Felber Dietrich D, Schwartz J, Schindler C, Gaspoz JM, Barthélémy JC, Tschopp JM, et al. Effects of passive smoking on heart rate variability, heart rate and blood pressure: an observational study. Int J Epidemiol 2007;36(4):834-840.

29. Pérez BF, Méndez GA, Lagos RA, Vargas MSL. Mucociliary clearance system in lung defense. Rev Med Chil 2014;142(5):606-615.

30. Stannard W, O'Callaghan C. Ciliary function and the role of cilia in clearance. J Aerosol Med 2006;19(1):110-115. 